\title{
Comparative Study between Efficacy of Two Quadruple DAAs Therapy in Treatment of HCV Relapsers
}

\author{
Amgad A. Elzahaby ${ }^{(1)}$, Kamel S. Hammad ${ }^{(2)}$, Waleed M. Mousa ${ }^{(1)}$, Ahmed S. Elkhapaty ${ }^{(3)}$ \\ (1) Department of Tropical Medicine and Gastroenterology, ${ }^{(2)}$ Department of Clinical pathology, \\ Faculty of Medicine, Al-Azhar University, Cairo, ${ }^{(3)}$ Kafr-Elsheikh Liver Research Center of Hepatology \\ Corresponding author: Ahmed S. Elkhapaty, Mobile: 01024203148, email: drahmeds3d.as@ gmail.com
}

\begin{abstract}
Background: Chronic hepatitis $\mathrm{C}$ virus (HCV) is considered as a major cause of liver diseases. The standard treatment of HCV infection is a combination of direct-acting antiviral agents (DAAs). Relapse is defined where HCV RNA remained undetectable at the end of therapy but rebounded to pretreatment levels once DAA therapy was discontinued. Aim of the study: This study was performed to compare efficacy and safety of two quadruple DAAs regimens (Sofosbuvir/Daclatasvir/Simeprevir and Ribavirin Vs. Sofosbuvir/Ombitasvir/ Paritaprevir/ ritonavir - Ribavirin) in treatment of HCV relapsers.

Patients and Methods: Retrospective cross-sectional study of 90 experienced patients previously treated with Sofosbuvir and Daclatasvir \pm Ribavirin for 3 months and relapsed. The patients were divided into two groups, each group included 45 patients: Group I treated with (Sofosbuvir and Daclatasvir -simeprevir-Ribavirin) while Group II treated with (Sofosbuvir-Ombitasvir/Paritaprevir/ritonavir - Ribavirin).

Results: The study showed an excellent response to both regimens of treatment. In group I; the sustained virologic response rates at 24th week were 44/45 (97.8\%); 100\% (29/29) in non-cirrhotic and 93.8\% (15/16) in cirrhotic patients. while group II SVR 24 rates were 93.3\% (44/45); 92.9\% (26/28) of non-cirrhotic patients, and $94.1 \%$ (16/17) of cirrhotic patients. while group II SVR 24 93.3\% (44/45) of overall patients, 92.9\% (26/28) of non-cirrhotic patients, and 94.1\% (16/17) of cirrhotic patients. Additionally, the most common adverse events reported were easy fatiguability, headache, nausea, generalized weakness, photosensitivity - in group I only.

Conclusion: It could be concluded that the current combination regimen is well tolerated and achieved excellent SVR rates.
\end{abstract}

Keywords: two quadruple DAAs therapy, HCV relapsers.

\section{INTRODUCTION}

HCV infection causes both acute and chronic hepatitis. Incident infection is associated with early symptoms in about $20 \%$ of persons. Spontaneous clearance occurs within six months of infection in 15$45 \%$ of infected individuals in the absence of treatment. The remaining 55-85\% develop chronic infection, which can lead to progressive fibrosis and cirrhosis. The risk of cirrhosis ranges from $15 \%$ to $30 \%$ after 20 years of infection with $\mathrm{HCV}^{(\mathbf{1})}$.

WHO estimated that in 2015, 71 million persons were living with chronic HCV infection worldwide (global prevalence: $1 \%$ ) and that 399,000 had died from cirrhosis or hepatocellular carcinoma (HCC) every year ${ }^{(\mathbf{1})}$.

The highest prevalence of HCV infection is present in Egypt, with $92.5 \%$ of patients infected with genotype 4, $3.6 \%$ patients with genotype $1,3.2 \%$ patients with multiple genotypes, and $<1 \%$ patients with other genotypes (2). It should be evident that treatment failure with direct acting antiviral agents is rare, occurring in approximately $5 \%$ of patients. The most common pattern of virological failure with

DAA therapy is due to relapse, where HCV RNA remained undetectable at the end of therapy but rebounded to pretreatment levels once DAA therapy was discontinued ${ }^{(3)}$.

The aim of the current study was to comparing efficacy and safety of two different regimens of quadruple DAAs therapies (Sofosbuvir plus Daclatasvir, Simeprevir and Ribavirin) Versus. (Sofosbuvir plus Ombitasvir, paritaprevir/ ritonavir and Ribavirin Regimen) of treatment of HCV relapsers after Sofosbuvir plus Daclatasvir with or without Ribavirin therapy.

\section{PATIENTS AND METHODS}

This retrospective cross-sectional study included a total of $90 \mathrm{HCV}$ infected patients previously treated with Sofosbuvir and Daclatasvir \pm Ribavirin for 3 months but detectable HCV RNA within 24 weeks of completing treatment, attending at Kafr Elsheikh Research Center of Hepatology. Written informed consent from all the subjects were obtained. This study was conducted between January 2017 to December 2017.

\section{Ethical approval:}

Current protocol was approved by the ethical committee of the Department of Tropical Medicine and Committee of Faculty of Medicine, Al-Azhar university, and then by the ethical committee, AlAzhar university. Permission obtained from Egyptian National Committee for Control of Viral Hepatitis (NCCVH).

The patients were divided into two groups, each group included 45 patients: Group I treated with (Sofosbuvir and Daclatasvir -simeprevir-Ribavirin) while Group II treated with (SofosbuvirOmbitasvir/Paritaprevir/ritonavir - Ribavirin). 
Inclusion criteria: All inclusion criteria were abided according to the Egyptian National HCV Control Program December 2016:

- All patients tested positive HCV RNA and previously treated with Sofosbuvir, Daclatasvir \pm Ribavirin

- $\quad$ The age $\geq 18$.

- Age $\geq 65$ years old should undergo cardiological assessment by ECG, Echo and cardiological consultation prior to therapy.

Exclusion criteria: All exclusion criteria were abided according to the Egyptian National HCV Control Program guidelines:

1. child's $\mathrm{C}$ cirrhotic patient.

2. Platelet count less than $50,000 / \mathrm{cmm}$

3. HCC, except 6 months after intervention aiming at cure with no evidence of activity by dynamic imaging (CT or MRI).

4. Extrahepatic malignancy except after two years of disease-free interval, in case of lymphomas and chronic lymphocytic leukemia, treatment can be initiated immediately after remission based on the treating oncologist report, pregnancy or inability to use contraception and in adequately controlled diabetes mellitus ( $\mathrm{Hb} \mathrm{A} 1 \mathrm{c}>9 \%)$.

5. HCV Naïve patient.

Clinical Examination: - All patients were subjected to complete history taking, which include history of other comorbid conditions such as DM, Cardiac disease and renal failure. History of previous treatment with antiHCV medicines (e.g. peg interferon plus ribavirin, Sofosbuvir plus Ribavirin, or other combination regimens) was also evaluated. Sensitivity to any other drug had to be checked out, full clinical examination: which include manifestations of chronic liver disease (such as jaundice, flapping tremors, lower limb edema, organomegaly, ascites) and obesity (BMI).

Laboratory Investigations: complete blood count (CBC), alanine aminotransferase (ALT, ), aspartate aminotransferase (AST), albumin, total bilirubin \& direct bilirubin, prothrombin time and INR, creatinine, urea, Alpha Fetoprotein (AFP), PCR at baseline (day 0).

Imaging: Patients were submitted to screening with the following procedures: Abdominal Ultrasonography: which include; liver size, echogenicity, portal and splenic vein diameters, splenic size, amount of ascites if present.

Treatment dose and period: : Group I treated with (Sofosbuvir 400mg One tablet once daily, Daclatasvir 60 mg One tablet once daily -Simeprevir $150 \mathrm{mg}$ One tablet once daily -Ribavirin $200 \mathrm{mg}$ Two capsules in the morning and 3 in the evening if body weight $<75 \mathrm{~kg}$ or Three capsules in the morning and 3 in the evening if body weight $\geq 75 \mathrm{~kg}$ (or less if dose reduction needed) for 12 weeks. while Group II treated with (Sofosbuvir 400mg One tablet once daily. Ombitasvir - Paritaprevir- Ritonavir (Tablets containing $12.5 \mathrm{mg}$ of Ombitasvir, $(75 \mathrm{mg}$ of paritaprevir and $50 \mathrm{mg}$ of ritonavir) Two tablets once daily - Ribavirin $200 \mathrm{mg}$ Two capsules in the morning and 3 in the evening if body weight $<75 \mathrm{~kg}$ or Three capsules in the morning and 3 in the evening if body weight $\geq 75 \mathrm{~kg}$ (or less if dose reduction needed) for 12 weeks.

Monthly follow up: All patients were submitted to the following investigations every 4 weeks; Routine clinical examination, laboratory investigation: CBC, ALT, AST, Bilirubin. Real time HCV PCR at the $24^{\text {th }}$ week after end of treatment.

\section{Data interpretation}

Sustained Virologic Response (SVR)and safety of different regimens. Data handling by Biostaticain.

Statistical Analysis: Recorded data were analyzed using the statistical package for social sciences, version 20.0 (SPSS Inc., Chicago, Illinois, USA).

\section{RESULTS}

This study was aimed to Compare the efficacy and safety of two regimens of quadruple therapies (Sofosbuvir and Daclatasvir -Simeprevir- Ribavirin versus Sofosbuvir-Ombitasvir /Paritaprevir/RitonavirRibavirin) of treatment of $\mathrm{HCV}$ relapsers after Sofosbuvir and Daclatasvir +/ Ribavirin therapy.

From January 2017 to December 2017. Ninety patients were enrolled and treated at Kafr Elsheikh Research Center of Hepatology, Egypt. The patients were divided into two groups, each group studied included 45 patients:

Group I: SOF-SIM-DAC-RBV 26 males $(57.8 \%)$ versus 19 females $(42.2 \%)$ with mean age 50.09 while Group II: SOF-OMP-PAR-RBV included 29 males $(64.4 \%)$ versus 16 females $(35.6 \%)$ with mean age 52.00 . Also, mean BMI was 27.78 in Group I studied while was 27.21 in Group II.

Group I and Group II samples showed no statically significant differences in components of complete blood count before receiving treatment. Mean values of $\mathrm{HB}$ were 13.36 and 13.88 in both groups respectively with $p$ value (0.123). While in WBCs they were 5950 and 6750 in both groups respectively with $\mathrm{p}$ value $(0.046)$. In platelets they were 170840 and 166730 in both groups respectively with $\mathrm{p}$ value $(0.777)$.

In Group I, mean values of $\mathbf{H B}$ before and after treatment were 13.36, $11.58 \mathrm{~g} / \mathrm{dl}$ respectively. In Group II mean values of HB before and after treatment were $13.88,11.76 \mathrm{~g} / \mathrm{dl}$ respectively. So, there is significant correlation between receiving theses quadruple therapies and decrease of HB (P value < 0.001) and (P value < 0.001) of Group I and Group II respectively.

Table (1): Comparison between both groups according to baseline data. This shows no statistically significant 
difference between groups according to demographic data.

\begin{tabular}{|c|c|c|c|c|}
\hline $\begin{array}{l}\text { Demographic } \\
\text { Data }\end{array}$ & $\begin{array}{l}\text { Group I: SOF-SIM-DAC-RBV } \\
(n=45)\end{array}$ & $\begin{array}{l}\text { Group II: SOF-OMP-PAR-RBV } \\
(n=45)\end{array}$ & $\mathbf{t} / \mathbf{x} 2 \#$ & $\begin{array}{l}\text { p- } \\
\text { value }\end{array}$ \\
\hline $\begin{array}{l}\text { Age (years) } \\
\text { Mean } \pm \text { SD } \\
\text { Range }\end{array}$ & $\begin{array}{l}50.09 \pm 8.89 \\
32 \_67\end{array}$ & $\begin{array}{l}52.00 \pm 11.01 \\
21 \_78\end{array}$ & 0.821 & 0.367 \\
\hline $\begin{array}{l}\text { Gender } \\
\text { Male } \\
\text { Female }\end{array}$ & $\begin{array}{l}26(57.8 \%) \\
19(42.2 \%)\end{array}$ & $\begin{array}{l}29(64.4 \%) \\
16(35.6 \%)\end{array}$ & $\begin{array}{l}0.421 \\
\#\end{array}$ & 0.517 \\
\hline $\begin{array}{l}\text { BMI }\left[\mathbf{w t}(\mathbf{h t}) /^{\wedge} \mathbf{2}\right] \\
\text { Mean } \pm \text { SD } \\
\text { Range }\end{array}$ & $\begin{array}{l}27.78 \pm 4.84 \\
21 \_45\end{array}$ & $\begin{array}{l}27.21 \pm 5.61 \\
6.4 \_34\end{array}$ & 0.273 & 0.602 \\
\hline
\end{tabular}

$t$-Independent Sample t-test; \# $x^{2}:$ Chi-square test

p-value $>0.05 \mathrm{NS}$

Table (2): Comparison between groups according to albumin, INR, creatinine, Fib4 calculation and alpha fetoprotein. This shows no statistically significant difference between groups according to Albumin (g/dl), INR, Creatine (mg/dl) and degree of fibrosis.

\begin{tabular}{|c|c|c|c|c|}
\hline & $\begin{array}{l}\text { Group I: SOF-SIM-DAC-RBV } \\
(n=45)\end{array}$ & $\begin{array}{l}\text { Group II: SOF-OMP-PAR-RBV } \\
(n=45)\end{array}$ & $\begin{array}{l}\text { t- } \\
\text { test }\end{array}$ & $\begin{array}{l}\text { p- } \\
\text { value }\end{array}$ \\
\hline $\begin{array}{l}\text { Albumin }(\mathbf{g} / \mathbf{d l}) \\
\text { Mean } \pm \text { SD } \\
\text { Range }\end{array}$ & $\begin{array}{l}4.08 \pm 0.70 \\
3.1 \_7.6\end{array}$ & $\begin{array}{l}3.95 \pm 0.47 \\
3 \_5.2\end{array}$ & $\begin{array}{l}1.13 \\
1\end{array}$ & 0.291 \\
\hline $\begin{array}{l}\text { INR } \\
\text { Mean } \pm \text { SD } \\
\text { Range } \\
\end{array}$ & $\begin{array}{l}1.00 \pm 0.21 \\
0.5 \_1.5\end{array}$ & $\begin{array}{l}1.04 \pm 0.16 \\
0.6 \_1.4\end{array}$ & $\begin{array}{l}0.61 \\
5\end{array}$ & 0.435 \\
\hline $\begin{array}{l}\text { Creatinine } \\
\text { (mg/dl) } \\
\text { Mean } \pm \text { SD } \\
\text { Range }\end{array}$ & $\begin{array}{l}0.82 \pm 0.18 \\
0.4 \_1.1\end{array}$ & $\begin{array}{l}0.93 \pm 0.54 \\
0.4 \_1.45\end{array}$ & $\begin{array}{l}1.29 \\
6\end{array}$ & 0.198 \\
\hline $\begin{array}{l}\text { Fib4 Calculation } \\
\text { Mean } \pm \text { SD } \\
\text { Range } \\
\end{array}$ & $\begin{array}{l}2.89 \pm 2.30 \\
0.49 \_9.24\end{array}$ & $\begin{array}{l}2.93 \pm 2.66 \\
0.51 \_15.51\end{array}$ & $\begin{array}{l}0.00 \\
6\end{array}$ & 0.937 \\
\hline $\begin{array}{l}\text { AFP (units) } \\
\text { Mean } \pm \text { SD } \\
\text { Range }\end{array}$ & $\begin{array}{l}13.06 \pm 2.74 \\
5-20\end{array}$ & $\begin{array}{l}14.01 \pm 2.96 \\
6-19\end{array}$ & $\begin{array}{l}1.58 \\
0\end{array}$ & 0.118 \\
\hline
\end{tabular}

Table (3): Comparison between laboratory data before and after treatment (at end of treatment) in group I: SOF-SIMDAC-RBV $(n=45)$. This shows statistically significant difference between groups according to $\mathrm{Hb}$, total bilirubin, ALT and AST

\begin{tabular}{|l|l|l|l|l|l|}
\hline Group I: SOF-SIM-DAC-RBV $(\boldsymbol{n = 4 5 )}$ & Before & After & Diff. & Paired t-test & p-value \\
\hline Hb $(\mathbf{g} /$ dl) & $13.36 \pm 1.63$ & $11.58 \pm 1.62$ & $-1.77 \pm 2.15$ & 5.515 & $<0.001^{* *}$ \\
\hline Plateletsx10^3/mm^3 & $170.84 \pm 73.67$ & $179.78 \pm 99.49$ & $8.93 \pm 78.92$ & -0.759 & 0.452 \\
\hline WBCx10^3/mm^3 & $5.95 \pm 1.60$ & $5.67 \pm 2.11$ & $-0.28 \pm 2.04$ & 0.927 & 0.359 \\
\hline Total Bilirubin (mg/dL) & $0.87 \pm 0.35$ & $1.38 \pm 0.71$ & $0.51 \pm 0.72$ & -4.763 & $<0.001^{* *}$ \\
\hline ALT (IU/L) & $34.11 \pm 14.14$ & $28.18 \pm 11.30$ & $-5.93 \pm 3.66$ & 10.862 & $<0.001^{* *}$ \\
\hline AST (IU/L) & $32.42 \pm 14.02$ & $26.82 \pm 11.07$ & $-5.60 \pm 3.60$ & 10.430 & $<0.001^{* *}$ \\
\hline
\end{tabular}

$t$-Paired Sample t-test

p-value >0.05 NS; *p-value <0.05 S; **p-value <0.001 HS 
ejhm.journals.ekb.eg

Table (4): Comparison between laboratory data before and after treatment in group II: SOF-OMP-PAR-RBV ( $\mathrm{n}=45)$. This shows statistically significant difference between groups according to $\mathrm{Hb}$, total bilirubin, WBC, ALT and AST.

\begin{tabular}{|l|l|l|l|l|l|}
\hline $\begin{array}{l}\text { Group II: SOF-OMP-PAR-RBV } \\
(\boldsymbol{n}=45)\end{array}$ & Before & After & Diff. & $\begin{array}{l}\text { Paired t- } \\
\text { test }\end{array}$ & p-value \\
\hline Hb $(\mathbf{g} / \mathbf{d l})$ & $13.88 \pm 1.59$ & $11.76 \pm 1.55$ & $-2.12 \pm 2.48$ & 5.740 & $<0.001^{* *}$ \\
\hline Plateletsx10^3/mm^3 & $166.73 \pm 63.26$ & $181.40 \pm 54.20$ & $14.67 \pm 76.22$ & -1.291 & 0.204 \\
\hline WBCx10^3/mm^3 & $6.75 \pm 2.13$ & $5.54 \pm 2.09$ & $-1.21 \pm 3.13$ & 2.604 & $0.013^{*}$ \\
\hline Total Bilirubin (mg/dL) & $0.89 \pm 0.34$ & $1.31 \pm 0.60$ & $0.42 \pm 0.69$ & -4.116 & $<0.001^{* *}$ \\
\hline ALT (IU/L) & $32.58 \pm 10.00$ & $26.91 \pm 8.44$ & $-5.67 \pm 2.83$ & 13.440 & $<0.001^{* *}$ \\
\hline AST (IU/L) & $33.60 \pm 11.46$ & $27.73 \pm 9.21$ & $-5.87 \pm 3.21$ & 12.263 & $<0.001^{* *}$ \\
\hline
\end{tabular}

$t$-Paired Sample t-test

p-value >0.05 NS; *p-value <0.05 S; **p-value <0.001 HS.

Table (5): Comparison between groups according to PCR(SVR 24) in cirrhotic and non cirrhotic patients. This shows no statistically significant difference between groups according to PCR in cirrhotic and non cirrhotic patients

\begin{tabular}{|l|l|l|l|l|}
\hline $\begin{array}{l}\text { PCR After( at 24 } \\
\text { week })\end{array}$ & $\begin{array}{l}\text { Group I: SOF-SIM-DAC-RBV } \\
(\boldsymbol{n}=\mathbf{4 5})\end{array}$ & $\begin{array}{l}\text { Group II: SOF-OMP-PAR-RBV } \\
(\boldsymbol{n}=\mathbf{4 5})\end{array}$ & X2 & $\begin{array}{l}\text { p- } \\
\text { value }\end{array}$ \\
\hline $\begin{array}{l}\text { Cirrhotic } \\
\text { Negative }\end{array}$ & $\begin{array}{l}16(94.1 \%) \\
1(5.9 \%)\end{array}$ & 0.47 & 0.493 \\
Positive & $15(93.8 \%)$ & $26(92.9 \%)$ & 0 & \\
\hline $\begin{array}{l}\text { Non Cirrhotic } \\
\text { Negative }\end{array}$ & $1(6.3 \%)$ & $2(7.1 \%)$ & 0.55 & 0.456 \\
Positive & $29(100.0 \%)$ & $0(0.0 \%)$ & 5 & \\
\hline
\end{tabular}

Table (6): Adverse events after retreatment (SOF-OMP-PAR-RBV) Vs. (SOF-SIM-DAC-RBV) of patients. This shows no statistically significant difference between groups

\begin{tabular}{|c|c|c|c|c|c|c|}
\hline \multirow[t]{2}{*}{ Side effect Overall patients } & \multicolumn{2}{|c|}{$\begin{array}{l}\text { Group I: SOF- } \\
\text { SIM-DAC-RBV } \\
(n=45)\end{array}$} & \multicolumn{2}{|c|}{$\begin{array}{l}\text { Group II: SOF- } \\
\text { OMP-PAR-RBV } \\
(n=45)\end{array}$} & \multicolumn{2}{|c|}{ Chi-square test } \\
\hline & No. & $\%$ & No. & $\%$ & $\mathbf{x}^{2}$ & p-value \\
\hline Patients & 45 & $100.0 \%$ & 45 & $100.0 \%$ & 0.000 & 1.000 \\
\hline Any adverse event during treatment & 38 & $84.4 \%$ & 35 & $77.8 \%$ & 0.281 & 0.596 \\
\hline Adverse event leading to discontinuation & 0 & $0.0 \%$ & 0 & $0.0 \%$ & 0.000 & 1.000 \\
\hline Serious adverse events & 0 & $0.0 \%$ & 0 & $0.0 \%$ & 0.000 & 1.000 \\
\hline \multicolumn{7}{|l|}{ Common AEs } \\
\hline fatigue & 16 & $35.6 \%$ & 12 & $26.7 \%$ & 0.468 & 0.494 \\
\hline Headache & 11 & $24.4 \%$ & 15 & $33.3 \%$ & 0.489 & 0.485 \\
\hline Nausea & 14 & $31.1 \%$ & 11 & $24.4 \%$ & 0.225 & 0.635 \\
\hline Vomiting & 3 & $6.7 \%$ & 5 & $11.1 \%$ & 0.132 & 0.717 \\
\hline Asthenia & 15 & $33.3 \%$ & 13 & $28.9 \%$ & 0.050 & 0.823 \\
\hline Abdominal trouble & 12 & $26.7 \%$ & 6 & $13.3 \%$ & 1.757 & 0.185 \\
\hline Pruritus & 3 & $6.7 \%$ & 3 & $6.7 \%$ & 0.000 & 1.000 \\
\hline Insomnia & 5 & $11.1 \%$ & 5 & $11.1 \%$ & 0.000 & 1.000 \\
\hline Photosensitivity & 3 & $6.7 \%$ & 0 & $0.0 \%$ & 1.393 & 0.238 \\
\hline Irritability & 4 & $8.9 \%$ & 6 & $13.3 \%$ & 0.108 & 0.742 \\
\hline
\end{tabular}

$x^{2}:$ Chi-square test

$p$-value $>0.05 \mathrm{NS} ; *$ p-value $<0.05 \mathrm{~S}$ 
This decrease in HB level is probably due to ribavirin and this is with agreement with Fried et al. (4) that found that Ribavirin causes a dosage-dependent hemolytic anemia ribavirin (1000-1200 mg/2day). In addition, ribavirin-associated anemia, in recent studies, appears to be much lower than seen in the past, may be due to the absence of the bone marrow-suppressant effects of peg-INF- $\alpha{ }^{\left({ }^{(5)}\right.}$.

we found a significant decrease in the WBC count in group II only $(6.75-5.54 \times 103 / \mathrm{mm} 3)$ before and after treatment respectively $\mathrm{P}$ value $=(0.013)$. Tong et al (6) allocated 128 patients with chronic HCV infection (30.5\% had compensated cirrhosis) into 4 groups. In the group that was treated with $\mathrm{SOF} / \mathrm{RBV}$ for 24 weeks neutropenia developed only in $19.4 \%$ (12/62) of patients.

In our study, the decrease in the mean WBC count in Group II was in agreement with the results reported by Elsharkawy et al. ${ }^{(7)}$, who found a significant decrease in the WBC count in 8 Egyptian patients with cirrhosis treated with SOF/RBV for 24 weeks with a mean difference in the mean WBC count of $-1.84 \times 103 / \mathrm{mm} 3$ between pretreatment and the end of treatment. However, in the same study 17 patients with cirrhosis treated with SOF/DAC $\pm \mathrm{RBV}$ had a non-significant increase in the mean WBC count of $0.18 \times 103 / \mathrm{mm} 3$ at the end of treatment compared to the pretreatment mean WBC count, which was inconsistent with our results.

In both groups of the current study, a significant decrease in the mean levels of transaminases (AST and ALT) during treatment. (P value $=<0.001)$ was found .

This occurred in Group I as follow: mean values of ALT before and after treatment were (32.5- 26.91) respectively. While those of AST before and after treatment were (33.60-27.73) respectively (Table 3). In group II mean values of ALT before and after treatment were (32.58 - 26.91) respectively. While those of AST before and after treatment were $(33.60$ - 27.73) respectively (Table 4). According to Total Bilirubin; mean values were before and after treatment were 0.87 , $1.38 \mathrm{mg} / \mathrm{dl}$ and $0.89,1.31 \mathrm{mg} / \mathrm{dl}$ in Group I and Group II respectively that statistically significant difference between groups. So, there is significant correlation between receiving these quadruple therapy and hyperbilirubinemia ( $\mathrm{P}$ value $<0.001$ ).

In agreement with our results, Hézode et al. ${ }^{(8)}$ that showed increase in serum conjugated bilirubin level with Sofosbuvir-Daclatasvir-Simeprevir Plus Ribavirin in Direct-Acting Antiviral-Experienced Patients with Hepatitis C. Also, EASL (9) recommended that the adverse reactions with patients receiving simeprevir mild, transient hyperbilirubinemia not accompanied by changes in other liver parameters was observed in approximately $10 \%$ of cases.

In patient who received SOF/OBV/PTV/r + RBV hyperbilirubinemia Shafran et al. ${ }^{(10)}$ showed that $1 / 21$ patient who received SOF/OBV/PTV/r + RBV developed hyperbilirubinemia. This finding can be explained by RBC haemolysis due to RBV, which leads to an increase in the mean indirect bilirubin level. This finding was in agreement with those of Abd-Elsalam et al. ${ }^{(11)}$, who found a significant increase in the mean total bilirubin level of $1.7 \mathrm{mg} / \mathrm{dl}$ during treatment of 2400 Egyptian patients with cirrhosis treated with SOF/RBV for 6 months. However, this finding was not in agreement with those of Elsharkawy et al. ${ }^{(12)}$ who reported that 12 Egyptian patients with cirrhosis who received SOF/DAC \pm RBV for 12 weeks and 37 Egyptian patients with cirrhosis who received SOF/RBV for 24 weeks developed a non-significant increase in the mean total bilirubin level at the end of treatment. As regards to response to treatment in our study, high rates of SVR were observed in treatment-experienced patients receiving SOF with DCV/SMV plus RBV was $44 / 45$ (97.8\%) SVR24 rates were $100 \%(29 / 29)$ and $93.8 \%$ $(15 / 16)$ in non-cirrhotic and cirrhotic patients, respectively.

In agreement with our finding, Abdel-Moneim et al. ${ }^{(13)}$, found that $97 \%$ (89/92) of patients who received SOF/DCV/SMV plus RBV achieved SVR12. SVR12 rates were 99\% (70/71) and 91\% (19/21) in non-cirrhotic and cirrhotic patients, respectively.

Also, Lawitz et al. ${ }^{(14)}$ concluded that 12-week treatment of SOF/DCV/ SMV was safe and well tolerated, and achieved $100 \%$ SVR12 in cirrhotic patients with portal hypertension or decompensated liver disease. Also, Hézode et al. ${ }^{(8)}$, reported that $60 \%$ of DAA experienced patients treated with combination of SOF/DCV/ SMV plus RBV achieved SVR at 12 weeks. The study included a small group of 12 patients only.

On the other hand, the efficacy results clear that patients retreated with SOF/OBV/PTV/r + RBV achieved an excellent SVR24 rate; 93.3\% (44/45) of overall patients, 92.9\% (26/28) of non-cirrhotic patients, and $94.1 \%$ (16/17) of cirrhotic patients.

In agreement with our finding, the QUARTZ II-III study investigated the strategy of combining three DAAs: $\mathrm{SOF}+\mathrm{OBV} / \mathrm{PTV} / \mathrm{r}$ with or without RBV in treatmentnaïve patients with $\mathrm{HCV}$ genotype 2 or genotype 3 infection without cirrhosis or with compensated cirrhosis. The combination regimen of $\mathrm{SOF}+\mathrm{OBV} / \mathrm{PTV} / \mathrm{r}$ with RBV for 8 weeks revealed that SVR12 rate was achieved by $90 \%$ in patients with genotype 2 infection. Moreover, the treatment for 12 weeks with SOF +OBV/PTV/r \pm RBV achieved SVR 12 by $98 \%$ of patients with genotype 3 infection ${ }^{(9)}$. Additionally, Flisiak et al. ${ }^{(15)}$ reported, in real-world evidence, an excellent antiviral potency of OBV/PTV/r/dasabuvir (DSV)/ RBV in the treatment of HCV GT1 and 4, the SVR12 was achieved by $99 \%$ (207/209) of overall patients, the SVR12 rates ranging from 96 to $100 \%$ across subgroups. Also, Wedemeyer et al. ${ }^{(16)}$, in another trial, concluded that OBV/PTV/r +DSV \pm RBV regimen demonstrated high rates of SVR12 in clinical trials for the treatment of HCV GT 1 and 4. The overall SVR12 rates were $96.8 \%$ for GT1 and $98.9 \%$ for GT4.

The safety profile of the current DAAs combination regimen was favorable, and tolerability of regimen was mostly mild or moderate in our patient cohort. The main 
Side effects were Fatigue (35.6-26.7\%), headache (24.4$55.6 \%)$, Asthenia (53.3-37.8\%), pruritus $(6.7-6.7 \%)$, Photosensitivity (6.7\%-0.0\%), Irritability (8.9- 13.3\%) in Group I and Group II respectively.

Other S/E vomiting (6.7-11.1\%), abdominal trouble (26.7-13.3\%), in Group I and Group II respectively (table 6). There were no deaths recorded, no serious AEs were reported and no discontinuation of the treatment.

Also Abdel-Moneim et al. ${ }^{(5)}$ Concerning safety and tolerability of SOF/SIM /DCV plus RBV, adverse events were reported in 64 patients $(70 \%)$ and generally were mild and transient. The most common AEs observed across all treatment arms during and after 12 weeks of follow-up included fatigue (24\%), headache (21\%), asthenia (19\%), nausea (12\%), and abdominal troubles $(11 \%)$. There were no deaths recorded, and only three serious adverse events were reported but did not cause discontinuation of the treatment

large study (327 patients) that reported that the main $\mathrm{S} / \mathrm{E}$ of SOF +OBV/PTV/r + RBV were fatigue (59\%), headache $(36 \%)$, nausea (34\%) and insomnia (25\%). Shafran et al. ${ }^{(9)}$ reported that the most common adverse events observed in patients of GT2 and GT3 received $\mathrm{OBV} / \mathrm{PTV} / \mathrm{r}+\mathrm{SOF} \pm \mathrm{RBV}$ for 12 weeks were fatigue and headache. Andreone et al. ${ }^{(17)}$ reported that although ribavirin is mainly associated with pruritus, asthenia, and insomnia, most of these adverse events were mild in severity. In addition, ribavirin-associated anemia, in recent studies, appears to be much lower than seen in the past, may be due to the absence of the bone marrowsuppressant effects of peg-INF- $\alpha$. Also Abdel-Moneim et al. ${ }^{(13)}$ the most common adverse events observed across all treatment arms during and after follow-up for 12 weeks included a headache (22\%), fatigue (20\%), asthenia (18\%), dyspnea (17\%), nausea (14\%), and abdominal troubles (13\%). Moreover, a decrease in hemoglobin concentration (11\%) was recorded. The data revealed that there were no deaths and discontinuations recorded due to serious adverse events that showed in four treated patients (inpatient hospitalization due to anemia).

\section{CONCLUSION}

The current combination regimen was well tolerated and achieved excellent SVR rates. The choice of combining multiple DAAs with different viral targets may be an effective treatment strategy in treatment HCV relapsers.

\section{RECOMMENDATIONS}

Further studies should be done to evaluate efficacy of these regimens of DAAs in HCV relapsers.

\section{REFERENCES}

1.World Health Organization (2018): guidelines for the care and treatment of persons diagnosed with chronic hepatitis $\mathrm{c}$ virus infection. https://www.who.int > hepatitis > publications > hepatitisc-guidelines-
2.Omran D, Alboraie M, Zayed R, Wifi M, Naguib M, Eltabbakh M et al .(2018): Towards hepatitis c virus elimination: egyptian experience, achievements and limitations.World J Gastroenterol. , 24(38): 4330-4340.

3.Wyles D, Dvory-Sobol H, Svarovskaia Doehle E et al.(2017): Posttreatment resistance analysis of hepatitis $\mathrm{C}$ virus from phase 2 and 3 clinical trials of ledipasvir/sofosbuvir. J Hepatol .,66:70310.

4. Fried MW, Shiffman ML, Reddy KR et al. (2002): Peginterferon alfa-2a plus ribavirin for chronic hepatitis $C$ virus infection. N Engl J Med., 347 (13): 975-82.

5. Abdel-Moneim A, Aboud A, Abdel-Gabbar M, Zanaty $M$ and Ramadan M (2018): Retreatment Efcacy of Sofosbuvir/Ombitasvir/Paritaprevir/

Ritonavir + Ribavirin for Hepatitis C Virus Genotype 4 Patients. Digestive Diseases and Sciences , 63:1341-1347

6. Tong M J, Chang PW, Huynh TT, Rosinski AA and Tong LT(2016): Adverse events associated with ribavirin in sofosbuvirbased therapies for patients with chronic hepatitis C: A community practice experience. Journal of Digestive Diseases , 17: 113-121.

7. Elsharkawy A, Eletreby R, Fouad R, Soliman Z, Abdallah M, Negm M, Esmat G(2017): Impact of different sofosbuvir based treatment regimens on the biochemical profile of chronic hepatitis C genotype 4 patients. Expert review of Gastroenterology \& hepatology , 11(8): 773-778.

8. Hézode C, Fourati S, Chevaliez S, Scoazec G, Soulier A, Varaut A et al.(2017): Sofosbuvir-daclatasvir-simeprevir plus ribavirin in direct-acting antiviral-experienced patients with hepatitis C. Clin Infect Dis., 64(11):1615-1618

9. European Association for the Study of the Liver (2016): EASL Recommendations on Treatment of Hepatitis C 2016. J Hepatol., 60: $392-420$

10. Shafran SD, Shaw D, Charafeddine M et al.(2018): Efficacy and safety results of patients with HCV genotype 2 or 3 infection treatedwith ombitasvir/paritaprevir/ritonavir and sofosbuvir with or without ribavirin (QUARTZ II-III). J Viral Hepat., 25(2):118-125

11. Abd Elsalam S, Sharaf Eldin M, Soliman S, Elfert A, Badawi R, Ahmad YK(2018): Efficacy and safety of sofosbuvir plus ribavirin for treatment of cirrhotic patients with genotype 4 hepatitis C virus in real life clinical practice. Arch Virol ., 163: 5156.

12.Elsharkawy A, Fouad R, El Akel W, El Raziky M, Hassany M, Shiha G et al. (2017):Sofosbuvir-based treatment regimens: real life results of 14409 chronic HCV genotype 4 patients in Egypt. Aliment Pharmacol Ther ., 45: 681-687.

13. Abdel-Moneim A, Aboud A, Abdel-Gabbar M, Zanaty MI, Ramadan M(2018): A sofosbuvir-based quadruple regimen is highly effective in HCV type 4-infected Egyptian patients with DAA treatment failure. J Hepatol.,68:1313-1315.

14. Lawitz E, Poordad F, Guterrez J, Kakuda T, Picchio G, Beets G et al. (2017):Simeprevir, daclatasvir and sofosbuvir for hepatts $\mathrm{C}$ virus-infected patients with decompensated liver disease. Viral Hepat ., 24: 287-294

15. Flisiak R, Janczewska E, Wawrzynowicz-Syczewska $M$ et al.(2016):Real-world efectiveness and safety of ombitasvir/paritaprevir/ritonavir \pm dasabuvir \pm ribavirin in hepatitis C: AMBER study. Aliment Pharmacol Ther.,44:946-956

16. Wedemeyer H, Craxí E, Zuckerman A et al.(2017): Real world efectiveness of ombitasvir, paritaprevir, ritonavir, dasabuvir, ribavirin in patients with hepatitis $C$ virus genotype 1 or 4 infection A meta-analysis. J Viral Hepat. ,24:936-943.

17. Andreone P, Colombo MG, Enejosa JV et al.(2014): ABT450, ritonavir, ombitasvir, and dasabuvir achieves $97 \%$ and $100 \%$ sustained virologic response with or without ribavirin in treatment-experienced patients with HCV genotype $1 \mathrm{~b}$ infection. Gastroenterology, 147:359-365. 